\title{
Shear Bond Strength of Brackets Bonded With Different Led Units \& Curing Times and at Different Debond Times in an In-Vitro Study
}

\author{
Chanamallappa Ramappa Ganiger ${ }^{1^{*}}$, Yusuf Ahammed $A R^{1}$ and Vikram Shetty ${ }^{2}$ \\ ${ }^{1}$ Deptartment of Orthodontics and Dentofacial Orthopaedics, School of Dental Sciences, KIMSDU, Karad, India \\ ${ }^{2}$ Deptartment of Orthodontics and Dentofacial Orthopaedics, Tatyasaheb Kore Dental College, New Pargaon, Warnanagar, Kolhapur, India
}

*Corresponding authors: Chanamallappa Ramappa Ganiger, Professor \& Head, Deptartment of Orthodontics \& Dentofacial Orthopaedics, School Of Dental Sciences, KIMSDU, Karad, India, Tel: (02164) 241555; E-mail: channapparganiger@gmail.com

Received date: August 26, 2017; Accepted date: September 11, 2017; Published date: September 18, 2017

Copyright: (C) 2017 Ganiger CR, et al. This is an open-access article distributed under the terms of the Creative Commons Attribution License, which permits unrestricted use, distribution, and reproduction in any medium, provided the original author and source are credited.

\begin{abstract}
Objective: The study compared 2 Light Emitting Diode (LED) curing units with a universal testing machine for checking the shear bond strength and also evaluated adhesive remnant index (ARI).

Methods: This in vitro study was carried out on sound 120 human extracted premolars. All the teeth were bonded with adhesive precoated metal brackets. The brackets were instantly set in place and confidently pressed against the tooth surfaces and polymerization of brackets was done with LED curing units [VALO and ELIPAR]. Both groups were further divided according to different debond times. SBS values in all the cases were measured at a crosshead speed of $1 \mathrm{~mm} / \mathrm{min}$ and a $50-\mathrm{kg}$ load cell. Significance for all statistical tests was pre-determined at $p<.05$.

Results: In-vitro bond strengths for the LED curing units (Elipar and VALO) were $8.84 \pm 3.141 \mathrm{MPa}$ and $9.87 \pm$ $5.591 \mathrm{MPa}$, respectively. Moreover, the shear bond strength was improving with time from 12 hours to 7 days in both the units. An equivalent distribution of the ARI (Adhesive Remnant Index) scores of 0, 1, and 3 was noticed for all debond times but an ARI score of 2 was not observed in this group. However, in LED unit (VALO) all the ARI scores $(0,1,2,3)$ were observed at different deboning times.
\end{abstract}

Conclusions: The results revealed that the shear bond strength (MPa) improved with time from 12 hours to 7 days in both the curing units.

Keywords: Curing lights; Bond strength; Debond time; Orthodontic brackets

\section{Introduction}

Curing devices have been developing in line with up-coming innovations in the dental field $[1,2]$. Dentistry has experienced a terrific progression, beginning from the technique of enamel acid etching since 1955. Similarly, the direct bonding of brackets on the teeth revolutionized the branch of Orthodontics [3].

The primary used light source for curing the composite resins used halogen bulbs. Their spectrum of radiation is continuous over the visible range. The halogen curing lights have several limitations as only $1 \%$ of its total energy input is converted into light and rest is generated as heat. This heat can lead to discoloration of the reflectors $[4,5]$.

Even though conventional halogen lights have been used for decades still their curing time was inconvenience to clinicians [6]. Therefore, Light-cured materials were developed for bonding the brackets in clinical orthodontic practice based on numerous advantages, including less working period and effortless removal of excess material [7]. Also, according to intensity of conventional halogen lamps (300 to $400 \mathrm{~mW}$ ), LEDs emit energy at levels up to the intensity of $1600 \mathrm{~mW}$, and plasma arc lamps up to $2000 \mathrm{~mW}[8,9]$.

LEDs have a probable lifetime above 10,000 hours and vibration with extremely little failure percentage. LED curing units have also shown advanced mean scores of shear bond strengths (SBS) when the cure time was raised from 10 seconds to 40 seconds [10-12].

In recent times, fresh LED curing light units (VALO Ortho; Ultradent Products, South Jordan, Utah) and (Elipar S10; 3M Unitek, Monrovia, Calif), hve been commercially available for bonding the brackets [12]. As it has a high-intensity light waves, so it might cure the adhesive materials within 3 seconds. Very few data is published in relation to this curing technique. Therefore, in this in vitro study 2 LED curing units were examined and compared with a universal testing machine for checking shear bond strength and also evaluated adhesive remnant index (ARI) at with different emission intensities and at different curing times using a universal testing machine.

\section{Materials and Methods}

This in vitro study was conducted on 120 human premolar teeth without dental caries or filling that had been extracted for therapeutic purpose in patients undergoing orthodontic therapy. After extraction, the teeth were cleaned to remove blood, periodontal soft tissue, calculus and debris and were gently stored in distilled water containing crystal of thymol in closed container at room temperature until preparation and testing.

Instantly before the bonding procedures, polishing on the buccal surfaces was done with a rubber cup and polishing paste for 30 seconds and air-dried. Enamel of buccal surfaces were etched with a $35 \%$ phosphoricacid gel 30 seconds. After this process, all the teeth were 
Page 2 of 4

washed with water spray and air dried with compressed air for 5 seconds.

All the 120 extracted premolars were bonded with adhesive precoated metal brackets (3M Unitek). Each bracket was removed from its individual blister pack immediately before placement. The application of bracket was in a consistent layer of adhesive primer (Transbond XT Primer) on the enamel of buccal surface, and the resin cement (Transbond XT Light Cure Orthodontic Adhesive) on the base of the brackets. The brackets were right away set in place and confidently pressed against the buccal tooth surfaces. After placement excess adhesive flash was removed and polymerization for all the brackets was done with LED curing units [VALO (for 3 seconds) and ELIPAR (for 10 seconds)].

The Light intensity of both the curiing systems was measured using a radiometer (Curing Radiometer Model 100 Demetron Research Corp., Danbury, CT, USA) before bonding. Both the study groups were subdivided into 3 groups $(n=20)$ according to the debond times: after 12 hours (a), 24 hours (b) and 7 days (c).

SBS values were noted at a crosshead speed of $1 \mathrm{~mm}$ per min and with a $50-\mathrm{kg}$ load cell. The force was directly recorded in $\mathrm{N}$ (Newtons) and converted into MPa (megapascal).

The enamel surfaces were examined with a stereomicroscope (Stemi 2000-C; Carl Zeiss, Go" ttingen, Germany) at a magnification of 10 to determine the amount of composite resin remaining according to the adhesive remnant index (ARI). ARI ranged from 0 to 3, following the scores defined as:

$0=$ no adhesive left on the tooth surface;

$1=$ less than half of the adhesive left on the tooth surface;

$2=$ more than half of the adhesive left on the tooth surface;

$3=$ adhesive totally left on the tooth surface with a distinct impression of the bracket mesh [13].

Descriptive statistics, with the mean and standard deviation, were calculated for each of the study groups tested. Tukey's test was used to categorize the groups in a uniform division, and the ARI scores were compared by means of the Chi-square test. Significance for all statistical tests was pre-determined at $\mathrm{p}<.05$.

\section{Results}

In-vitro bond strengths for the LED curing units (Elipar and VALO) were $8.84 \pm 3.141 \mathrm{MPa}$ and $9.87 \pm 5.591 \mathrm{MPa}$, respectively. The results were significant in case of Elipar unit but not in VALO. Moreover, the shear bond strength was improving with time from 12 hours to 7 days in both the units as mentioned in Tables 1 and 2 .

\begin{tabular}{|l|l|l|l|l|l|}
\hline $\begin{array}{l}\text { LED unit } \\
\text { (Elipar) }\end{array}$ & No & Mean & SD & F value & Sig. \\
\hline 12 hours & 60 & 8.2 & 1.603 & & \\
\hline 24 hours & 60 & 8.4 & 1.429 & 5.761 & 0.004 \\
\hline 7 days & 60 & 9.93 & 4.846 & & \\
\hline Total & 180 & 8.84 & 3.141 & & \\
\hline $\begin{array}{l}\text { LED unit } \\
\text { (VALO) }\end{array}$ & No & Mean & SD & F value & Sig. \\
\hline
\end{tabular}

\begin{tabular}{|l|l|l|l|l|l|}
\hline 12 hours & 60 & 9.17 & 3.928 & & \\
\hline 24 hours & 60 & 10.2 & 6.025 & 0.715 & 0.49 \\
\hline 7 days & 60 & 10.25 & 6.508 & & \\
\hline Total & 180 & 9.87 & 5.591 & & \\
\hline
\end{tabular}

Table 1: Means and standard deviations of the shear bond strengths (MPa).

\begin{tabular}{|l|l|l|l|}
\hline $\begin{array}{l}\text { (I) LED unit } \\
\text { (Elipar) }\end{array}$ & $\begin{array}{l}\text { (J) LED unit } \\
\text { (Elipar) }\end{array}$ & $\begin{array}{l}\text { Mean } \\
\text { Difference (I- } \\
\text { J) }\end{array}$ & Sig. \\
\hline 12 hours & 24 hours & -0.2 & 0.932 \\
\hline & 7 days & $-1.733\left(^{*}\right)$ & 0.006 \\
\hline 24 hours & 12 hours & 0.2 & 0.932 \\
\hline & 7 days & $-1.533\left(^{*}\right)$ & 0.018 \\
\hline 7 days & 12 hours & $1.733\left(^{*}\right)$ & 0.006 \\
\hline & 24 hours & $1.533\left(^{*}\right)$ & 0.018 \\
\hline
\end{tabular}

Table 2: Statistical comparison between the LED unit (Elipar S10; 3M Unitek, Monrovia, Calif) by means of the Tukey's Test; ${ }^{\star}$ The mean difference is significant at the .05 level.

The study also performed Tukey's Test for getting the mean difference of units at different time intervals. Elipar curing unit showed significant difference between 12 hours and 7 days only $(p=0.006)$ as shown in Table 2. However there was absence of significant differences in the values of VALO at different time intervals (Table 3 ).

\begin{tabular}{|l|l|l|l|}
\hline $\begin{array}{l}\text { (I) LED } \\
\text { unit } \\
\text { (VALO) }\end{array}$ & $\begin{array}{l}\text { (J) LED unit } \\
\text { (VALO) }\end{array}$ & $\begin{array}{l}\text { Mean Difference } \\
(\mathbf{I}-\mathrm{J})\end{array}$ & Sig. \\
\hline 12 hours & 24 hours & -1.033 & 0.571 \\
\hline & 7 days & -1.083 & 0.54 \\
\hline 24 hours & 12 hours & 1.033 & 0.571 \\
\hline 7 days & 7 days & -0.05 & 0.999 \\
\hline & 24 hours & 1.083 & 0.54 \\
\hline
\end{tabular}

Table 3: Statistical comparison between the LED unit (VALO Ortho; Ultradent Products, South Jordan, Utah) by means of the Tukey's Test; ${ }^{\star}$ The mean difference is significant at the .05 level.

The results of Table 4 declare that there was no significant difference in both the LED units as analyzed by Chi square test.

In LED unit (Elipar), an equivalent distribution of the ARI (Adhesive Remnant Index) scores of 0,1 , and 3 was noticed for all debond times but an ARI score of 2 was not observed in this group.

However, in LED unit (VALO) all the ARI scores $(0,1,2,3)$ were observed at different deboning times as illustrated in Table 4 . 


\begin{tabular}{|l|l|l|l|l|l|}
\hline $\begin{array}{l}\text { LED unit } \\
\text { (Elipar) }\end{array}$ & $\mathbf{0}$ & $\mathbf{1}$ & $\mathbf{2}$ & $\mathbf{3}$ & Sig. \\
\hline 12 hours & 8 & 5 & 0 & 4 & \\
\hline 24 hours & 6 & 5 & 0 & 2 & NS \\
\hline 7 days & 5 & 4 & 0 & 2 & \\
\hline $\begin{array}{l}\text { LED unit } \\
\text { (VALO) }\end{array}$ & 0 & 1 & 2 & 3 & Sig. \\
\hline 12 hours & 3 & 6 & 3 & 2 & \\
\hline 24 hours & 1 & 5 & 1 & 2 & NS \\
\hline 7 days & 0 & 5 & 0 & 4 & \\
\hline
\end{tabular}

Table 4: ARI (Adhesive Remnant Index) for the two different LED Groups.

\section{Discussion}

During functional movements, orthodontic brackets are usually subjected to shear, tensile forces, and/or sometime combination of all these factors. The adequate bond strengths to enamel surface for metal orthodontic brackets ought to be ranged between 8 and 9 shear bond strengths $(\mathrm{MPa})$, as these values are sufficient to resist standard orthodontic forces [12]. Hence, many researches have been accomplished to assess the correlation between adhesive bond strength and post-bonding time.

In the current study, the mean value shear bond strengths ( $\mathrm{MPa})$ for LED unit (Elipar) and LED unit (VALO) was $8.84 \pm 3.141 \mathrm{MPa}$ and $9.87 \pm 5.591 \mathrm{MPa}$, respectively and the figures were comparable with the previous studies [14].

The values were almost increasing with the increase in debonding times (from 12 hours to 7 days) and the maximum MPa was noticed at the debond time of 7 days for LED unit (Elipar) and LED unit (VALO) as $9.93 \pm 4.846$ and $10.25 \pm 6.508$ respectively. Similarly, Turka et al found that the mean shear bond strength at 24 hours $(17.61 \mathrm{MPa})$ was superior and the mean SBSs at $5 \mathrm{mins}(8.38 \mathrm{MPa})$ and at $15 \mathrm{mins}(9.91$ $\mathrm{MPa}$ ) [15]. Hajrassie, Khier also reported that SBS scores with orthodontic adhesives to metallic brackets enhance with the debonding time for both studies (in vivo and in vitro). The authors also stated that in vitro results are comparatively $40 \%$ superior than the results seen in vivo studies [16].

Previous studies also found significant differences among lights and curing times when comparing LED units with halogen based devices $[17,18]$. I a study by Usümez et al suggested that 20 seconds of LED exposure might generate shear bond strengths comparable to those obtained with halogen-based units for 40 seconds [17], however Swanson et al, found higher bond strengths were obtained with longer curing times. Although they found adequate bond strengths with even a 10- second cure, yet they recommended longer periods of polymerization [19].

In the present study, no significant difference was seen in both the LED units for ARI (Adhesive Remnant Index) values. The study also showed that LED unit (Elipar), had an equivalent distribution of the ARI scores of 0,1 , and 3 for all debond times but an ARI score of 2 was not seen in this group. Whereas in LED unit (VALO) all the ARI scores $(0,1,2,3)$ were observed at different deboning times.

Retamoso et al observed a similar distribution of the ARI scores of 1,2 , and 3 was in the control group during the first 30 minutes. It was also noticed that with saliva contamination, an elevated frequency of ARI scores of 1 . This indicates a sign of bond failure at the enamel \& adhesive interface [3]. Similarly other studies also found that the ARI frequencies did not disclose significant differences between the study groups [12,20,21].

Gomes et al found that shorter light exposure time was associated with reduced adhesive scores [22]. Abdullah et al also mentioned that ARI scores of in-vitro study noticed most of the adhesive stayed on the bracket after debonding, demonstrating that strength of the bond at the enamel \& composite interface was lesser than the bond at the bracket \& composite interface [23].

\section{Conclusions}

This in-vitro study, shear bond strengths (MPa) showed that both the protocols were sufficient for clinical usage. Furthermore, the shear bond strength was improving with time from 12 hours to 7 days in both the LED units.

\section{References}

1. Duke ES (2001) Light-emitting diodes in composite resin photo polymerization. Compend Contin Educ Dent 22: 722-725.

2. Dunn WJ, Taloumis LJ (2002) Polymerization of orthodontic resin cement with light-emitting diode curing units. Am J Orthod Dentofacial Orthop 122: 236-241.

3. Retamoso LB, Onofre NML, Hann L, Marchioro EM (2010) Effect of light-curing units in shear bond strength of metallic brackets: an in vitro study. Appl Oral Sci 18: 68-74.

4. Mills LF (1982) Status report: dental visible light-curing units. Council on Dental Materials, Instruments, and Equipment. J Am Dent Assoc 104: 505.

5. Stahl F, Ashworth SH, Jandt KD, Mills RW (2000) Light-emitting diode (LED) polymerization of dental composites: flexural properties and polymerization potential. Biomaterials 21: 1379-1385.

6. Sunna S, Rock WP (1998) Clinical performance of orthodontic brackets and adhesive systems: a randomized clinical trial. Br J Orthod 25: 283-287.

7. Pearson AI (1995) Optimal light curing of adhesive precoated brackets. J Clin Orthod 29: 583-585.

8. Sfondrini MF, Cacciafesta V, Scribante A, Klersy C (2004) Plasma arc versus halogen light curing of orthodontic brackets: a 12-month clinical study of bond failures. Am J Orthod Dentofacial Orthop 125: 342-347.

9. Fleming PS, Eliades T, Katsaros C, Pandis N (2013) Curing lights for orthodontic bonding: a systematic review and meta-analysis. Am J Orthod Dentofacial Orthop 143: 92-103.

10. Oesterle LJ, Shellhart WC, Belanger GK (1998) The use of bovine enamel in bonding studies. Am J Orthod Dentofacial Orthop 114: 514-519.

11. Buyukyilmaz T, Usumez S, Karaman AI (2003) Effect of self-etching primers on bond strength - are they reliable? Angle Orthod 73: 64-70.

12. Di Nicoló R, Araujo MAM, Alves LAC, Souza ROA, Rocha DM (2010) Shear bond strength of orthodontic brackets bonded using halogen light and light-emitting diode at different debond Times. Braz Oral Res 24: 64-69.

13. Artun J, Bergland S (1984) Clinical trials with crystal growth conditioning as an alternative to acid-etch enamel pretreatment. Am J Orthod 85: 333-340.

14. Verma P (2016) Curing efficiency of three light emitting diode units at different curing profiles. Indian J Dent Res 27: 168-173. 
Citation: Ganiger CR, Ahammed ARY, Shetty V (2017) Shear Bond Strength of Brackets Bonded With Different Led Units \& Curing Times and at Different Debond Times in an In-Vitro Study. Dentistry 7: 456. doi:10.4172/2161-1122.1000456

Page 4 of 4

15. Turka T, Turkb SE, Iscic D, Cakmakc F, Ozkalaycic N (2007) Saliva Contamination Effect on Shear Bond Strength of Self-etching Primer with Different Debond Times. Angle Orthodontist 77: 901-906.

16. Hajrassie MKA, Khier SE (2007) In-vivo and in-vitro comparison of bond strengths of orthodontic brackets bonded to enamel and debonded at various times. Am J Orthod Dentofacial Orthop 131: 384-390.

17. Usumez S, Buyukyilmaz T, Karaman AI (2004) Effect of light-emitting diode on bond strength of orthodontic brackets. Angle Orthod 74: 259-263.

18. Silta YT, Dunn WJ, Peters CB (2005) Effect of shorter polymerization times when using the latest generation of light-emitting diodes. Am J Orthod Dentofacial Orthop 128: 744-748.

19. Swanson T, Dunn WJ, Childers DE, Taloumis LJ (2004) Shear bond strength of orthodontic brackets bonded with light-emitting diode curing units at various polymerization times. Am J Orthod Dentofacial Orthop 125: 337-341.
20. Cal-Neto JP, Miguel AJ, Zanella E (2006) Effect of a self-etching primer on shear bond strength of adhesive precoated brackets in vivo. Angle Orthod 76: 127-131.

21. Mavropoulos A, Staud CB, Kiliaridis S, Krejci I (2005) Light curing time reduction: in vitro evaluation of new intensive light-emitting diode curing units. European J Orthod 27: 408-412.

22. Gomes P, Portugal J, Jardima L (2014) Effect of high-powered LED-curing exposure time on orthodontic bracket shear bond strength. Rev Port Estomatol Med Dent Cir Maxilofac 55: 78-82.

23. Abdullah Alper Oz, Aslihan Zeynep Oz, Selim Aricib (2016) In-vitro bond strengths and clinical failure rates of metal brackets bonded with different light-emitting diode units and curing times. Am J Orthod Dentofacial Orthop 149: 212-216. 